\title{
MICRORRELATOS Y MICROFORMAS. LA NARRACIÓN AUDIOVISUAL MÍNIMA
}

\author{
Microstorytelling and Microforms: the Minimal Audiovisual Narrative \\ Virginia Guarinos (Universidad de Sevilla) \\ http://dx.doi.org/10.12795/AdMIRA.2009.01.03
}

\begin{abstract}
Resumen. Una de las características de la narración del cine de hoy es la hibridación de géneros, la fragmentación y la crisis del relato clásico. Pero hay que añadir un nuevo elemento: la microforma. Existe una nueva forma de narrar propiciada por la cibercultura, las redes sociales, los blogs, la mensajería de teléfonos móviles y de correo electrónico que se ha estandarizado mundialmente. Esta nueva forma de relato breve, desde los microblogs hasta los comentarios en muros de redes sociales, está alcanzando a la ficción cinematográfica, que ha comenzado a generar ya no el tradicional cortometraje sino otras formas aún más breves como los micro y nanometrajes, junto con otros productos fanfiction que circulan por Internet, sobre el remontado de otros productos cinematográficos, por lo general largometrajes. La tradición literaria del cuento y el relato corto empieza a expandirse en el entorno audiovisual más allá de los modos habituales (videoclips, spots publicitarios, trailers). De los noventa minutos a los nueve segundos, las nuevas formas breves ficcionales se están generalizando en Europa y en América, como son ejemplos especialmente España y Colombia. Pero, ¿son realmente narrativos textos de veinte segundos o simplemente descriptivos?
\end{abstract}

\begin{abstract}
One of the features of today narrative cinema is hybridization of genres, fragmentation and the crisis in the classic storytelling. But there is another new element: the microform. There is a new form of narration from cyber culture, social networks, blogs, instant messaging on mobile phones and e-mail that has been standardized globally. This new form of short stories, from the comments to microblogs or walls in social networking, for example, is affecting fiction films, which has already begun to make not other traditional brief forms, even shorter, like the micro and nanofilms. The tradition of literary short story and tales begins to expand in the audiovisual environment beyond standard modes (video clips, advertising spots, coming attractions...). From ninety minutes to nine seconds movies, the new short fiction is becoming more widespread in Europe and America, like in Spain and Colombia (as festivals prove). But, are texts of twenty seconds really narrative? Or, are they simply descriptive?
\end{abstract}

Palabras clave. Relato audiovisual, formas breves, micro y nanometraje, historias narrativas, cine y cibercultura.

Keywords. Audiovisual storytelling, short forms, micro and nano films, narrative stories, cinema and cyber culture.

\section{INTRODUCCIÓN. Lo pequeño es bello}

Toda materia del universo es medible y el sistema internacional de unidades de medida establece las magnitudes fundamentales de temperatura, tiempo, masa y longitud. Para proceder a la medida exacta existe una serie de prefijos que a partir de la unidad significan aumento o disminución de la porción de materia elegida para su medición. 
Por encima de la unidad los prefijos deca-, hecto-, kilo-, mega- y giga- son inversos a los que dividen la unidad en segmentos cada vez más pequeños: deci-, centi-, mili-, micro-, y nano-. Lo micro se corresponde con un 0,000001 de la unidad; lo nano con un 0,000000001. Los textos audiovisuales también son medibles y, si bien, la proporción de reducción no es exacta a la milésima como en las ciencias experimentales, la reducción temporal que están alcanzando los relatos (y también las historias) audiovisuales actuales justifica la denominación relativamente reciente empleada para determinadas producciones: micro y nanometrajes.

Las píldoras informativas de diversos canales o los microespacios informativos de televisión son detectables en todas las cadenas. Todos ellos son microtextos. Pero cuando a la brevedad temporal se le suma la aparición de acción y ficción, llegamos a los microrrelatos. Los programas de sketches ficcionales tienen presencia en cada televisión, al estilo Camera café o Escenas de matrimonio (Tele 5), Saturday Night Live (Cuatro), Estados carenciales (La Sexta); e incluso los segmentos de autorreferencia

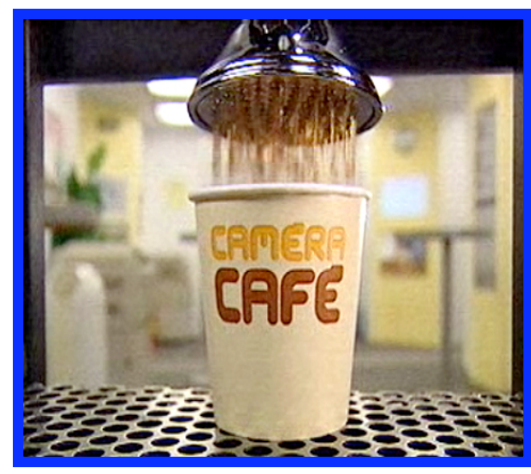
(como los de esta temporada 2009 en Cuatro) poseen pequeñas historias, algunas de ellas encadenadas por la serialidad $^{1}$. En el conjunto macrodiscursivo de la programación televisiva, este hecho no sería novedoso, sobre todo si tenemos en cuenta que la fragmentación del relato y el espacio múltiple y fragmentario son características de la postelevisión (Imbert, 2008). Sin embargo, la proliferación de estos productos ficcionales excede a características de un medio y hablan de un modo de hacer extendido que afecta a la mayor parte de medios y sistemas de comunicación, convirtiéndose en una forma de expresión de la cultura narrativa social de los inicios del siglo XXI.

Aunque la literatura siempre ha contado con ellos, en el área audiovisual la publicidad ha sido siempre "consumidora" de relatos breves para su expresión televisiva y en estos momentos ve en ellos una vía imprescindible: "Ya no hay que producir marcas sino historias: es la era del relato" (Silió, 2009: 24); así habla Juan García-Escudero, de

\footnotetext{
${ }^{1}$ Como la protagonizada por ejemplo por Iñaki Gabilondo y Pablo Motos huyendo de un peligro.
} 
Delvico, al considerar que la población no quiere ver publicidad y hay que ofrecerle un formato atractivo, siendo lo mejor para ello usar historias que se puedan contar y que el relato oral del boca a boca entre en funcionamiento. $\mathrm{Y}$, efectivamente, no hay ningún medio o discurso audiovisual con posibilidades narrativas que haya experimentado más con el microrrelato que la publicidad. Fuera de esta tradición publicitaria, hoy proliferan los talleres de microrrelatos, los concursos radiofónicos ${ }^{2}$ en los que se propone a los oyentes la creación de pequeñas historias, el uso didáctico de formas breves en las escuelas.

Pero a pesar de esta proliferación audiovisual, existe una descompensación entre los objetos de estudio y los propios estudios desde el cotejo cuantitativo. Hay poco escrito de guión para cortometrajes, poco sobre análisis de cortometrajes, sobre la construcción del relato breve audiovisual, siendo lo más abundante la publicación de historia de los cortos. Ello demuestra una clara desventaja con respecto a estudios literarios donde hay mucho investigado sobre cuento o relato corto, bien es cierto que el objeto mismo de estudio es diferente; aunque el relato corto en literatura sea

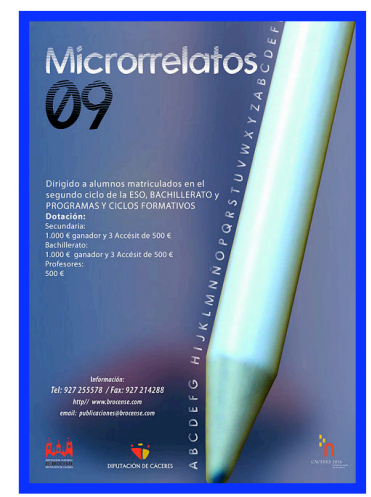
un género, y no menor por su extensión y mucho menos por los literatos que lo han cultivado, el cortometraje ha sido durante mucho tiempo la puerta, el inicio de la carrera de quienes querían dedicarse a la dirección de largos, un medio más que un fin en sí mismo. Esto ha cambiado en los últimos años. Muchos directores consagrados recalan en el cortometraje por diversos motivos ${ }^{3}$ y muchos de ellos también hacen publicidad y videoclips musicales ${ }^{4}$, auténticas escuelas para la construcción de breves relatos audiovisuales.

\footnotetext{
${ }^{2}$ Es conocido el caso de la sección del escritor Juan José Millás en la Cadena SER, en La ventana de Gemma Nierga, que ha llegado a publicar los relatos en forma de libro (http://www.escueladeescritores.com/concurso-cadena-ser) (23/04/09), o los concursos de microrrelatos de Onda Polígono, ya en su tercera edición.

${ }^{3}$ El propio Pedro Almodóvar ha estrenado un corto a estas alturas de su carrera: La concejala antropófaga (2009), “un capricho", según el director.

${ }^{4}$ Por poner un ejemplo, los spots de una familia de hippies vegetarianos y el consumo de fiambre de pavo es muy elocuente en lo que respecta al dispositivo narrativo puesto en marcha en una breve composición que no llega al minuto (http://www.youtube.com/watch?v=ZYXr88Yw dg) (23/04709). O los seriados también de la bonoloto y el perro fiel, Pancho, que se independiza tras cobrar un boleto premiado (http://www.youtube.com/watch?v=JTbH4DJ9aLk\&feature=PlayList\&p=A18BB71C5F5EECA9\&index
} 
La idea de la fragmentación de la cultura postmoderna afecta de lleno a todos los relatos audiovisuales y ha calado hondo en la recepción del espectador. La llegada de la web 2.0 también ha revolucionado la pasión por la microforma (no hablamos de calidades). El gusto por el fragmento, por la lectura rápida con sentido completo en pocos minutos, está tan acorde a nuestros tiempos como para hacer incluso que los espectadores realicen sus propias versiones de casi todo: el fenómeno de la "versión del espectador"5 en Internet, en vez de la versión del director. La brevedad asequible de la duración de estas formas lleva a los creadores anónimos aficionados a producir estos relatos por intuición, muchos de ellos sin formación alguna, con una sabiduría basada en la observación y en la imitación, una forma autodidacta de aprender a interpretar y a realizar este tipo de productos que para las generaciones más jóvenes son connaturales a sus formas de ocio y cultura, como los remontados de secuencias de películas con nuevos doblajes de buen y mal gusto, casi todos con intenciones hilarantes buscando pasar un buen rato no sólo visionándolos como espectadores, también haciéndolos como creadores.

Microformas, microextensiones, microrrelatos, microhistorias, microdiálogos, microanálisis... y microtiempo. En todos estos términos la dimensión temporal se convierte más que en condicionante del relato en esencia óntica de los productos resultantes. En este sentido, la consideración del tiempo como parte de una manera particular de organizar el mundo queda reflejada también en la comunicación. Como

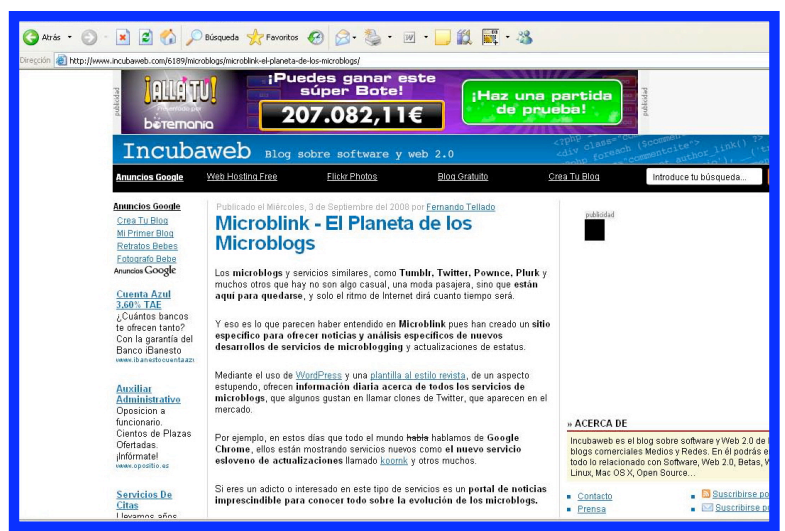

razona Gómez Vargas (2009: 15) “el tiempo adquiere procesos de modelización varios y un elemento básico para ello son lo sistemas interactivos y comunicativos que los moralizan. Es, por decirlo de una

=4) (23/04/09). De entre los videoclips musicales narrativos puede verse el correspondiente a la canción de David Bisbal, Dígale (http://www.youtube.com/watch?v=96UsW-gULuQ) (05/05/09).

${ }^{5}$ Así se encuentran secuencias remontadas de fan fiction de muchas de las películas o series de televisión favoritas de los espectadores o versiones personalizadas, dramatizadas de imagen real, y hasta con clicks de grandes obras del cine o la televisión, desde Los Simpson hasta Macbeth. 
manera, una forma de ver la comunicación en la dimensión temporal (...) En lo social y cultural, estas dimensiones de temporalidad se hacen presentes a través de elementos tecnológicos que moralizan los sistemas cognitivos, preceptuales y se materializan en sistemas de vida y prácticas culturales, es decir, los sistemas digitales interactivos que dinamizan la cultura mediática y abren un nuevo espacio antropológico como es el ciberespacial". En esta coordenada queremos encajar la necesidad de la microforma audiovisual. Blogs, chat, messenger, redes sociales de mensajería no instantánea están provocando un desarrollo de nuevas narrativas breves y en primera persona, autodiegéticas, que pueden llegar al límite de lo temporal en los microblogs ${ }^{6}$, por ejemplo.

Detrás de todo ello se esconde no sólo una cuestión estética, también propiamente cognitiva y explícitamente discursiva (Rincón, 2006). Y esta realidad de la sociedad red reestructura cognitivamente la construcción de los discursos que no son ciberespaciales. Los micro y nanometrajes son textos perfectos para el contacto con el relato de ficción a deshora, a la carta y con poco tiempo y peso, perfectos para entrar en plataformas como YouTube y otras de intercambio de archivos visuales. De hecho las propias televisiones se están planteando ya de modo efectivo la recepción individual, en función de la disponibilidad del tiempo de cada uno, en vez de la consideración del concepto de receptor de masas. No puede ser de otro modo en un momento en que se siguen realities por teléfono móvil, hay series pensadas ya sólo para Internet, donde la lengua escrita se ha contracturado para la mensajería sms o el correo electrónico. La simplificación de la forma y la condensación de los contenidos son necesarias en un universo esquematizado, comprimido, donde se ahorra tiempo de creación y recepción, donde poder contactar a través de portátiles desde cualquier parte y visionar cualquier cosa que debe ser breve.

\footnotetext{
6 Sobre el alcance de los microblogs véanse http://www.elpais.com/articulo/portada/imparable/auge/microblogs/elpeputeccib/20080117elpcibpor 2/T es y http://www.incubaweb.com/6189/microblogs/microblink-el-planeta-de-los-microblogs/ (26/04/09).
} 

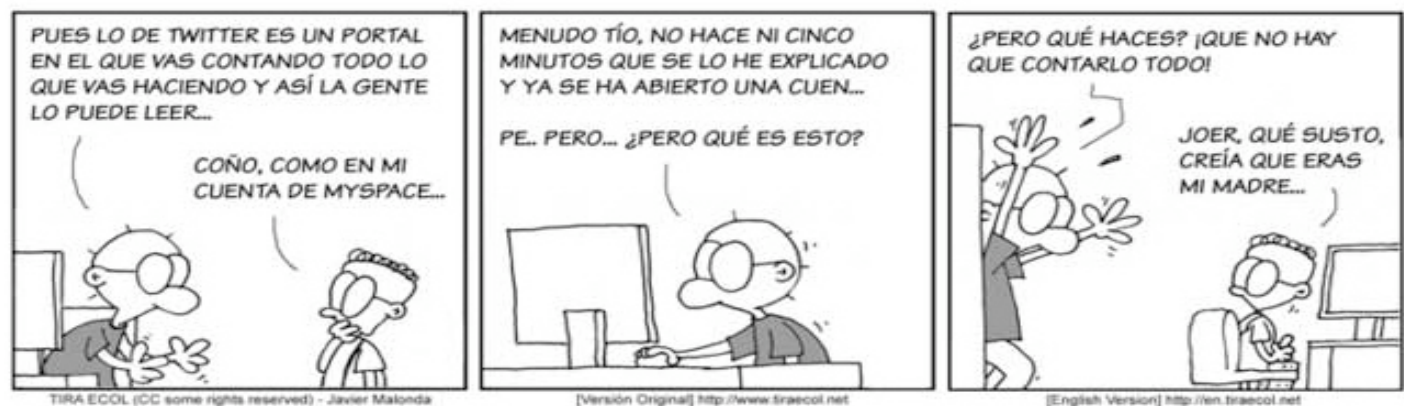

Por otro lado, la lectura no lineal del relato hipertextual influye en la construcción del propio relato y también en su duración. Para proteger al relato de lecturas fragmentarias, la escasez temporal es una aliada, y eso es lo que se consigue con textos tan breves ${ }^{7}$.

\section{OBJETIVOS Y METODOLOGÍA. El microanálisis fílmico}

Paradójicamente el microanálisis es un análisis completo, exhaustivo y minucioso de un fragmento seleccionado de una forma larga. Tal como lo explica Zunzunegui, esta actividad se cierne sobre "pequeños fragmentos, microsecuencias susceptibles de ser observadas bajo el microscopio analítico y en las que se pueda estudiar la condensación de la líneas de fuerza que constituyen el film del que se extirpa" (1996:15). En cualquier caso, la segmentación del objeto fílmico breve para su análisis no depende tanto de la fragmentación lineal sino de la descomposición del espesor en lo que al plano se refiere, en términos de Casetti, y en la media de lo posible de la linealidad o fragmentación propiamente dicha. Por otro lado, es necesario también aplicar la segmentación de la historia, su estructura y distribución de acontecimientos y transformaciones, contados y presupuestos, en definitiva, de la parte de historia imaginada.

En este caso, haremos "microanálisis" de una forma corta que termina convirtiéndose en microanálisis por la extensión del texto objeto de estudio. La metodología empleada es ésa y el objetivo es intentar, sobre la observación y el análisis, establecer los paradigmas narrativos que mueven una microforma ficcional fílmica, en busca de la tan llevada y

\footnotetext{
${ }^{7}$ Véase la página http://www.javeriana.edu.co/relato_digital/index.htm sobre narrativa digital (05/05/09).
} 
traída condensación de los relatos cortos, y al mismo tiempo confirmar si estamos ante narraciones o descripciones referenciales en muchos casos, prevaleciendo la puesta en escena sobre la puesta en serie y en cuadro. A este respecto, diferimos de las aportaciones teóricas desde la literatura y partimos de la idea de que el cortometraje no funciona por condensación de elementos, como tantas veces se ha repetido, sino por selección de los mismos y su posibilidad de sugerencia y juego con la competencia espectatorial. Zavala (2004), uno de los mayores expertos en narrativa breve, afirma que la narración actual en el cine ha sufrido una metamorfosis desde el canon clásico hasta la especialización narrativa de estrategias de condensación. Aun así, son muchas las características comunes entre el cuento y el relato breve literario y las microformas fílmicas que afectan no sólo al tiempo, también a las otras categorías narrativas básicas: espacio, personajes, enunciación y estructura.

\section{LA MICROFORMA NARRATIVA}

La tendencia a la brevedad iniciada con el siglo XX en las artes en general, llevada al extremo con el minimalismo, alcanza hoy límites de relatos de una sola frase, a veces hasta sin forma verbal. La larga tradición de obras artísticas literarias minúsculas ha sido correspondida con la existencia de una amplia gama de estudios teóricos y aplicados a la micronarración. No sucede así con el cortometraje cinematográfico. Ello ha propiciado que mientras en literatura se esté investigando ya la evolución del cuento clásico al moderno, posmoderno e hipertextual, en comunicación audiovisual estemos entrando en el análisis de la forma corta en general. No obstante, existe del mismo modo una evolución del cortometraje tradicional hasta llegar a los micro y nanometrajes, evolución que está siguiendo un camino muy parecido al transitado por los literatos.

La sistematización del cuento posmoderno de Zavala incluye elementos como que sea una obra rizomática, en proceso continuo de construcción donde es el lector quien termina de dar el sentido a un texto cargado de intertextualidad, con un aparente orden 
cronológico que simula contar una historia, con una presencia alta de metaficcionalidad, de realidades virtuales no explicitadas sino imaginadas, de ironía, y todo contado por un narrador irrelevante, cuando no desaparecido. El cuento hipertextual extrema al límite los elementos mostrando un relato fragmentario y lleno de paradojas estéticas, donde el lector es el protagonista. Además, el cuento posmoderno desarrolla un tiempo no claramente delimitado ni definido, un espacio que sólo está en la imaginación del lector, unos personajes paródicos, un narrador autoirónico. Casi la totalidad de estos caracteres son aplicables a las microficciones fílmicas, como también a otros objetos de arte y expresión, sin duda, marcadas por un espíritu de época, como se ha comentado con anterioridad.

De la misma manera que un cuento no es un hijo menor, sino un proyecto narrativo en sí mismo, el micrometraje también lo es y posee sus fines y su construcción deliberada, como afirma Lagmanovich (2006 b). Algunos ejemplos recogidos en trabajos de este mismo teórico (y práctico) nos muestran micorrrelatos literarios que llegan incluso a menos de veinte palabras, que, como bien dice su autor, sugieren la urgencia que expresan estos relatos, del tipo de éste de Miguel Saiz Álvarez, El globo:

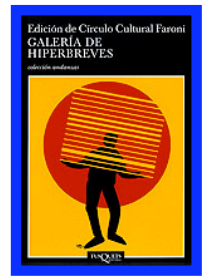
"Mientras subía y subía, el globo lloraba al ver que se le escapaba el niño" (de Galería de hiperbreves, 2001). "Esa rapidez o velocidad produce una sensación de inmediatez: anula la expectativa sobre qué va a ocurrir después, pues lo poco o mucho que se presenta ocurre simultáneamente, en un relámpago, frente a los ojos del lector" (Lagmanochiv, 2006 a). Se trata de un relato vertiginoso, como decía Zavala. Aforismos, haikus, máximas, greguerías quedarían fuera de la clasificación por no conllevar ficción según algunos teóricos de la literatura. Pero, ¿es sólo el contenido ficcional lo que debiera marcar la diferencia entre microtexto y microrrelato? Y, aun siendo ficcionales, ¿hay verdadero relato en "Es fácil juntar a Los Beatles. Sólo se necesitan tres balazos", o en "La primera mañana después de mi muerte" $"$, o únicamente descripción de situaciones?

\footnotetext{
${ }^{8}$ Pertenecen respectivamente a Orlando Enrique Van Bredam (Argentina) y se titula Graffiti (La vida te cambia los planes, 1994), y a José Costa Santiago (España), bajo el título de iSorpresa! (Galería de hiperbreves, Barcelona, Tusquets, 2001).
} 
Lo cierto es que algo muy parecido sucede con los micro y, más aún, con los nanometrajes audiovisuales, con los que comparten las características de:

- Brevedad

- Indisolubilidad del título con la historia

- Estructura in media res

- Simpleza sintáctica (también visual)

- Inmediatez de lo narrado

- Efecto emotivo y/o reflexivo único de sentido metafórico

- Intensidad en la provocación de tensión lectora

- Sentido paródico y humorístico (menos en ficciones fílmicas)

- Intertextualidad e hibridación

- Ruptura de convenciones sintáctico-gramaticales (también en los audiovisuales)

- Variación estructural por suspensión, sin resoluciones finales cerradas y unívocas

En el mundo audiovisual la clasificación de textos cortos no es fácil ${ }^{9}$, ni similar a la literaria. De un amplio grupo de microtextos marcados por la brevedad de su extensión tendríamos por un lado los segmentos de autorreferencia o las noticias, donde no hay ficcionalidad. Al resto de composiciones breves deberíamos llamarlos microrrelatos porque en ellos cabe la ficción. No obstante, algunos segmentos de autorreferencia televisivos, o las propias noticias contienen relatos, narración, aun fuera de lo ficcional. Los anuncios publicitarios, los videoclips musicales, los trailers... son todos textos cuya finalidad última no es la de contar una historia factual o ficcional, sino la de promocionar y vender una película, una canción o un producto comercial; no tienen intención última y única de contar una historia y la cuentan. Por ello, llamaremos microrrelatos a todo relato breve factual o no, aunque aquí nos centraremos en los textos que más claramente han optado por denominarse nanometrajes y micrometrajes, es decir, a los microrrelatos fílmicos, marcados físicamente como textos por la disminución temporal del cortometraje. Además de ello, de modo casual, de momento, dichas formas breves son ficcionales en su mayoría.

\footnotetext{
${ }^{9}$ Es cierto que hemos manejado clasificaciones y definiciones que en literatura están bastante extendidas, pero hay que considerar que estas mismas dudas existen entre los teóricos de la literatura como demuestran los títulos de algunos trabajos que están pensando sobre ello, como los de Gómez Trueba (2008), Ródenas (2008), Rivas (2008), Valls, (2001), Tejero (2001), Koch (2004) o Andrés (2005).
} 
Todas las formas breves audiovisuales, como afirma Pezzini, refiriéndose a trailers, spots y clips, "sono picoli testi, cioè, ad altísima coerenza e cohesione interna. Sono studiati e confezionati con la cura estrema di chi investe enormemente su di loro, no solo in termini di valori economici, ma anche e soprattutto in termini di vamori comunicativi, e affida loro la riuscita di una strategia di captaciones e contatto nei confronti del pubblico. Sono testi i cui diversi livelli di significaciones ci appaiono blindati, per trovare la forza anzitutto di riuscire a brillare, sia pure per un momento, nel flusso rumoroso cui sono destinati, e a svolgere la loro funzione di rinvio ad altri testi, altre situación, altre sotire, per i quali riuscire a suscitare almeno un poc di desiderio o nostalgia" (2005: 17). Esta esencialidad y eficiencia comunicativa de la brevedad ya fue defendida por Italo Calvino, quien hizo una elogio de la rapidez, poniéndose de lado del uso minucioso que la forma reducida hace del ritmo, de la economía y la lógica esencial para narrar, considerando la narración corta una batalla contra el tiempo para alcanzar el orden perdido o el objeto deseado. De sus estudios americanos o seis propuestas para el nuevo milenio, la rapidez es una entre la levedad, la exactitud, la visibilidad, la multiplicidad y la consistencia (Calvino, 1989), y no se equivocaba, aunque no todas ellas se cumplen a la vez en el caso de los relatos audiovisuales breves. Esta rapidez es la que obliga a la esencialidad, a la lógica de la condensación temporal y a la selección expresiva y estructural.

Si nos remontamos a los orígenes del cine, las primeras cintas no duraban más de lo que alcanzan algunos de los trabajos que aquí analizamos. Y aun así, no se trata de los mismos textos, de los mismos relatos, no sólo desde el punto de vista técnico, evidentemente, tampoco desde el estrictamente narrativo. Aquellos filmes primitivos de dos o tres minutos, de plano único, y encuadre casi también, carecían de lógica narrativa extraescénica. La puesta en serie termina de otorgar a los relatos cinematográficos su lenguaje y la unidimensionalidad espacio-temporal de los cortos arqueofílmicos no la contempla. A pesar de ello, ambos tipos de textos breves cuentan con la característica común de la monoconceptualidad, en tanto que los nano y micrometrajes suelen contemplar trama y tema únicos, con sólo un foco temático a desarrollar, una idea, un concepto. La microfabulación fílmica actual cuenta además con una intención creadora 
y narradora, no es una captación aséptica del mundo circundante. La propia elección del formato breve es ya en sí misma una voluntad creativa: las adaptaciones de relatos literarios breves a largometrajes, la adaptación de relatos de duración extendida a cortometrajes o la producción de cortometrajes, de trailers falsos o videoclips por placer de parte de directores consagrados así lo atestiguan ${ }^{10}$. El uso actual de la historia atómica no posee las mismas motivaciones, ni el mismo resultado narrativo. Adaptar una obra de Shakespeare con animación de plastilina en veinte minutos no nace del mismo origen ni llega al mismo resultado que las adaptaciones en mudo de la misma, que fueron muchas. La tradición oral origen del microrrelato literario, el "arte pigmeo", que algunos han llamado ${ }^{11}$, no es la del microcosmos audiovisual. El origen es mucho más reciente y se encuentra más en el material hibridado por el hipertexto, los videojuegos, la mensajería móvil e instantánea; en definitiva, con una lógica visual y narrativa distinta y distante del protocine y lógica consecuencia de la inter y transmedialidad. Como el género literario, no se trata (o no sólo) de una moda, ni de un instrumento, ya no es sólo esa primera oportunidad donde mostrar el arte de un director que es cortometrajista porque aspira a ser director de largos algún día.

De mayor a menor, largometraje es, según las academias de artes y ciencias cinematográficas, una película de duración superior a cuarenta minutos. No obstante, la duración media estandarizada es de noventa minutos. Mediometraje es una pieza audiovisual entre treinta y sesenta minutos. Cortometraje es el producto audiovisual de duración superior al minuto e inferior a los treinta minutos. Pero esta terminología se amplia ante la llegada de unidades menores, que aunque se emplean en el uso profesional y diccionarios especializados aún no tienen cabida en el Diccionario de la Real Academia Española.

\footnotetext{
${ }^{10}$ Los trabajos publicados sobre nuestro cine corto pueden corroborarlo, como los de Gutiérrez Carbajo (2004), Cerón (2002), Amitrano (1998), Cooper y Dacyger (1998), Sempere (2003).

${ }^{11}$ Como lo ha hecho Pedro de Miguel en El Mundo (http://www.elmundo.es/elmundolibro/microrrelatos/) $(12 / 04 / 09)$. Y no es la primera vez que la prensa diaria de nuestros días se preocupa por el tema. Puede leerse una interesante entrevista a Monterroso en El País (http://www.elpais.com/articulo/semana/microrrelato/quintaesencia/narrativa/elpepuculbab/20070901elpb abese_1/Tes) $(02 / 05 / 09)$.
} 


\section{NANO Y MICROMETRAJES}

\subsection{Qué son}

Al parecer de origen francés, el término micrometraje designa un corto no superior a

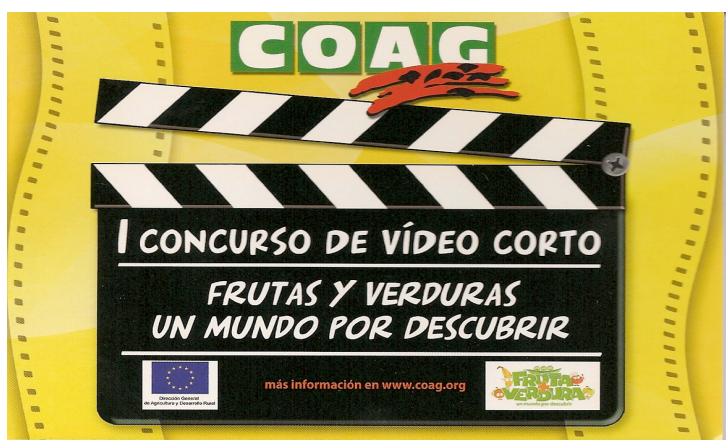
tres minutos. El nanometraje es una pieza menor aún que el micrometraje. En cualquier caso, no hay un concepto común de uso para diferenciar ambos términos al no haber sido fijada su definición. Son los festivales y concursos de uno $\mathrm{u}$ otro formato los que están definiendo la duración de estas piezas audiovisuales ${ }^{12}$. Lo más extendido es usar el término nanometraje para piezas entre treinta segundos y un minuto de duración. Pueden ser obras realizadas por profesionales pero los festivales y concursos incitan a la creación anónima, de la calle, aconsejando el uso de webcams o teléfonos móviles para las grabaciones, en un intento más de nuestro tiempo de alcanzar la democratización de la creación.

\subsection{Cómo se distribuyen o proyectan}

Básicamente este formato audiovisual se asocia a la cultura que estamos viviendo; no se trata sólo de la facilidad de creación, también de la de lectura. La aparición de dispositivos visuales pensados para recibir información en los desplazamientos (telefonía móvil, Ipod, Mp4, etc.) o la posibilidad de tiempo libre escaso para el ocio entre las horas de trabajo ha desarrollado la existencia de productos audiovisuales mínimos para este uso. En alguna página web se publicita la existencia de textos cortos pensados para "ese minuto necesario de relajo en la oficina" $"$. Casi todos ellos tienen fines no comerciales y son de acceso gratuito en la red. YouTube y otras plataformas de

\footnotetext{
${ }^{12}$ Véanse las siguientes bases de concursos de México, lugar que junto a Chile cuentan con una profusión de concursos y festivales: http://events.mx.msn.com/nanometrajes/manual.aspx? cp-documentid=453235. La ilustración es un cartel anunciador de un concurso de metraje corto, de máximo un minuto, para escolares de entre 8 y 14 años (2009).

13 Bajo el epígrafe de "Cine en la oficina" puede leerse esta frase en la página http://canaldesierto.bligoo.com/tag/nanometraje (10/05/09).
} 
vídeo sirven para canalizar sus visionados, como el de muchas otras producciones audiovisuales.

En 2008 MSN en México lanza su primer concurso de nanometrajes ${ }^{14}$ de alta repercusión. No obstante, la fiebre de la microformas en Latinoamérica, de amplia tradición de microformas literarias, es anterior y hace que en sus territorios se concentren buena parte de los concursos y festivales, incluso auspiciados por las universidades, como el caso de Chile, que va ya por el II Concurso de la Universidad del Desarrollo de Arte digital y micrometraje ${ }^{15}$, tras una primera edición donde se presentaron más de cuatrocientos trabajos. Todos estos festivales y encuentros son en su mayor parte virtuales y el gran territorio universal de exhibición es la red global. La obra Lo que tú quieras oír (Guillermo Zapata), sin licencia comercial es la obra más vista en YouTube de 2008: 70 millones de visionados ${ }^{16}$. En España, contamos con el Certamen de Cortometrajes-Express del Ateneo Cultural $1^{\circ}$ de Mayo, en el que, al estilo de los concursos de pintura express, los participantes cuentan con 48 horas para rodar, editar y entregar los trabajos, de cuatro minutos como máxima duración ${ }^{17}$.

\subsection{Categorías narrativas en las microformas fílmicas}

Aunque el uso y engranaje de las categorías narrativas adquieren particularidades extremas en las microformas de ficción audiovisual, existen otros elementos distintos de ellas que son tan o más importantes que ellas mismas:

- Título contextualizador. La brevedad temporal de un relato de estas características, como en el literario, hacen del elemento contextual un recurso necesario para situar y sugerir hacia dentro. El propio título del micro o nanometraje resulta fundamental, no sólo paratexto, en tanto que

\footnotetext{
14 En esta página pueden verse los cortos ganadores: http://events.mx.msn.com/nanometrajes (12/05/09).

15 En la página http://www.eje-zeta.com/2007/05/23/segundo-concurso-de-arte-digital-y-micrometraje/ (12/05/09). Y en esta otra, http://www.nanometrajes.cl/ (12(05/09) se pueden ver obras del concurso sobre nanometrajes que se celebra desde 2004 en Chile, que al cierre de estas páginas está abriendo la fecha de envío de obras para esta convocatoria 2009. Otro concurso de micrometraje urbano, desde la Facultad de Arquitectura en la Universidad Católica de Chile, puede verse en http://www.ieut.cl/arts/17/concurso-micrometraje-urbano/ (12/05/09).

${ }^{16} 80.808$ a fecha de $12 / 05 / 09$. En esta otra página se acumulan más de 700 nanometrajes que se pueden visionar: http://www.videos.es/b/nanometraje/ (12/05/09).

17 La convocatoria de 2008 puede verse en http://www.artespain.com/11-04-2008/concursos-yconvocatorias/i-certamen-de-cortometrajes-express (12/05/09).
} 
su focalización encauza la intencionalidad y el sentido de lo que se va a ver.

- Intertextualidad esencial. Por este mismo motivo de aprovechamiento de lo externo, la hibridación genérica y el apoyo en la intertextualidad redundan en elementos no ya de condensación sino de recurrencia a otros textos que de manera automática puedan venir a la memoria competente del espectador, supliendo así todo aquello que el guión no ha podido o querido decir por la limitación temporal.

- Sugerencia general. Uno de los elementos más frecuentes en casi todos los relatos brevísimos es la mudez que no el silencio. Palabras sueltas, frases sueltas, muy escasos diálogos... ceden su poder a nanometrajes mudos donde la imagen visual se ve cargada de sugerencia; sugerencia de lo que dicen o piensan los personajes y sugerencia del antes y del después de la historia. El nano y micrometraje inducen a imaginar la vida anterior y posterior al relato mostrado, ya que obliga al espectador a buscar muchas explicaciones previas para interpretar el presente con el que contacta.

De entre las recomendaciones que suelen darse para la elaboración de guiones ${ }^{18}$ aparece la necesidad de planteamiento, nudo y desenlace, es decir, de estructura tradicional, con un inicio impactante; se habla de ahorro de lo accesorio, de la construcción de personajes bajo esquemas estereotipados que faciliten la identificación y lectura del espectador, pero sin prescindir de la complejidad de los mismos, del uso de una experiencia audiovisual técnica híbrida que fusione imágenes reales, tratadas, infográficas y efectos dirigidos a la percepción multidimensional. Se aconseja a los guionistas de cortos suprimir las redundancias, acortar las frases, usar pocos personajes

\footnotetext{
18 Véase en la trilogía de artículos de W. Martel (2008). Otras páginas para guionistas son http://script4all.com/, http://www.visualwriter.com/HowTo/ShortScr.htm o el blog de la professional del guión Julie L. Gray quien afirma "How to tell an extraordinarily emotionally complex story in a simple way in a short space of time: simple plot, complex characters. If that formula is true of a feature script, it is a thousand times as true for a short script. Because you do not have 90 minutes to tell your story. You have 10 minutes. So writing a short script is not a free pass in which a writer doesn't need to bother with complexity and payoff. A short script doesn't ask less of you as a writer - it asks quite a lot more (...) If a feature script is a field of grapes harvested and turned into a barrel of wine, a short script is that barrel of wine turned into one jeweled glass of exotic, apricot-scented dessert wine. (http://rougewave.blogspot.com/2008/08/should-you-write-short-script.html 12/05/09).
} 
con conflictos no complejos... Philips (2001) apuesta por historias ininterrumpidas y cronológicas, historias sorprendentes, de diálogos concisos y útiles para dar a conocer la personalidad del personaje, sin tramas secundarias, donde el personaje nunca explique qué significa el relato. Y muchos de estos consejos para guiones de cortometrajes de duración normal aparecen puestos en práctica en los microrrelatos audiovisuales. Por ello, extremado hasta el final de sus consecuencias, los usos de las categorías narrativas ${ }^{19}$ resultan así:

- Modelos de mundo. La mayor parte de los nano y micrometrajes presentan modelos de mundo ficcionales verosímiles incluso en aquellos en que se recurre a la animación. No obstante, es posible encontrar ficcionalidad no verosímil y, en mucha menor medida, modelos de realidad efectiva. A pesar de todo ello, la retórica de la realidad está muy presente por la textura de las imágenes, en gran parte captadas a través de planos en movimiento por los dispositivos con los que se graban, en su mayoría domésticos.

- Estructuras narrativas por composición diegética. La brevedad de estos relatos hace poco factible el desarrollo de estructuras complejas que se desplieguen en diégesis principal y subdiégesis del tipo que sean. Muy al contrario, la diégesis única queda reducida a la mínima expresión en lo que a historia se refiere. La secuencia única es un hecho en este tipo de producciones audiovisuales. En la mayor parte de los casos puede llegar a coincidir secuencia con escena como única unidad, sin la posibilidad de despliegue de trama y subtramas. De hecho, sobre todo el nanometraje, plantea una situación y no un relato, un gag, como unidad mínima más de situación que de acción. De lo que se deduce que no se encuentran en ellos tramas y subtramas, ni plots principales y secundarios. El giro de guión suele suceder al final, planteando una variación estructural por

19 Además de otros visionados, ha sido objeto de análisis para este trabajo la siguiente "microfilmografía": Lost and found (Philip Brink, 2009), 60 segundos (http://www.revelacioneschucaras.com/2009/04/27/lost-found/), Cuatro palabras (Daniel Medina, 2008), 60 segundos (http://www.vimeo.com/2583903), Nana (José Javier Rodríguez Melcón, 2006), 30 segundos, mejor corto de ficción Premios Goya (http://www.youtube.com/watch?v=EyurhSZn6Pk), Don Fermín (Javier Pañella, 2005), 40 segundos, La carrera (sin créditos), 59 segundos, Micrometraje $n^{\circ} 4$ (Juan Pablo Arias, sin datar), 2 minutos, Tendencias (José Cordova, 2007), 45 segundos (http://www.nanometrajes.cl/), Pausa (Filip Carrasco, 2004), 35 segundos, Ochenta y ocho (Francisco Ramírez Murdoch, 2006), 42 segundos, Sueños de papel (Arturo Ibáñez, 2008), 45 segundos, (http://www.nanometrajes.cl/) y Siesta (Álvaro Ceppi, 2007), 30 segundos. 
sustitución al tiempo que por suspensión, y generando un final abierto cuya prolongación debe quedar suplida por el espectador.

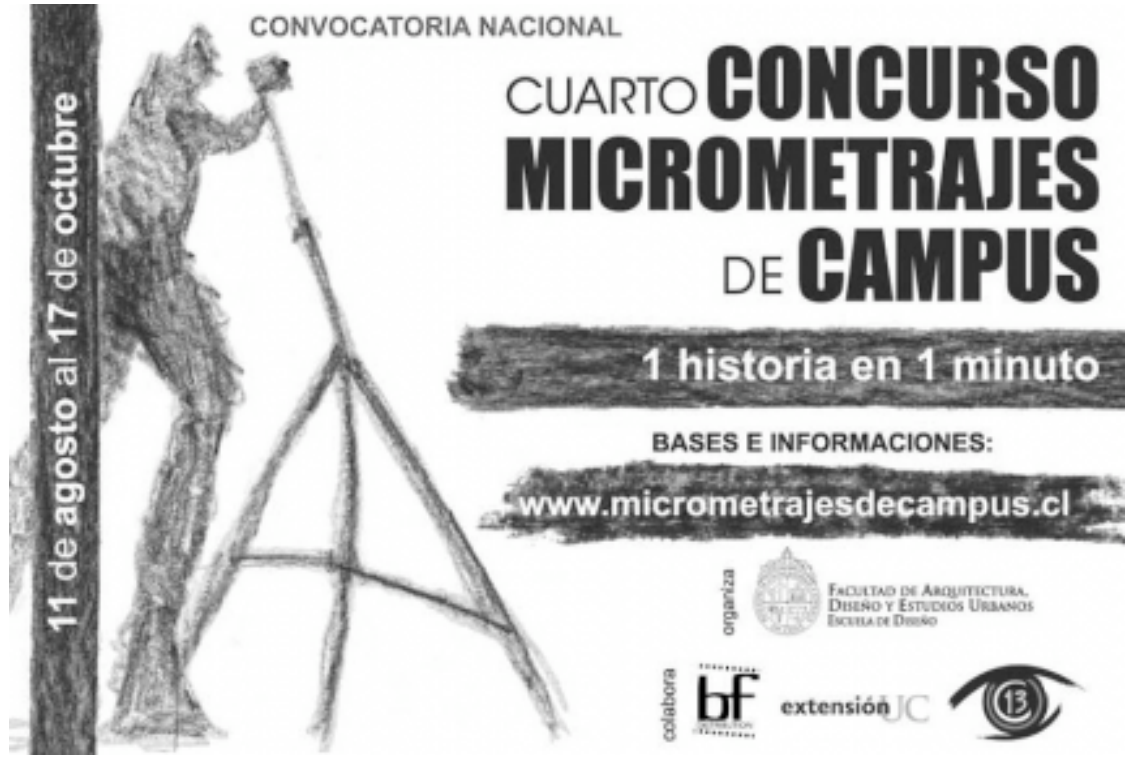

- Estructuras narrativas por composición temporal. Los mismos rasgos planteados en la composición diegética conducen a una organización temporal simple. La temporalidad es lineal y proyectiva, en la mayor parte de ellos sin juegos temporales de flashbacks. El tiempo escena o tiempo real es el dominante en los micro y nanometrajes, bien es verdad que se suele recurrir a recursos técnicos para dilatar o condensar el tiempo, a través del acelerado o ralentizado y hasta congelado de imágenes, al ritmo rápido de montaje y la microelipsis para reducir el desarrollo de la historia, especialmente los que hacen atisbo de planteamiento, nudo y desenlace.

- Enunciación. La maquinaria enunciativa que pone en marcha este miniengranaje se manifiesta a través del dominio casi total del showing con muy pocas oportunidades para el telling. Es de notar que la gran mayoría de los textos son mudos. Al carecer de palabra hablada se obstaculiza la creación de personajes pero también la de narradores. Se encuentran algunos casos sueltos de narradores homo e intradiegéticos, casi todos en monólogo de voz en off, pero casi ninguno de narradores extra/heterodiegéticos. De la misma manera las diversas formas de aparición de la focalización, del punto de vista cognitivo, resultan reducidas a la focalización externa, quedando conformadas al mínimo las focalizaciones internas y sus variantes e incluso las omniscientes. Y aun así, las marcas del sujeto de la enunciación son fuertes, pues hay por lo general en 
ellos un deseo de originalidad que incluye efectos diversos que "desficcionalizan", desmontando el dispositivo de invisibilidad de la enunciación.

- Personajes y acción. La fugacidad con la que aparecen los personajes no permite siquiera hablar de presencia de estereotipos, como tampoco de principales y secundarios. Sus actuaciones son tan simples que no los definen como esferas de acción; son más bien los rasgos indiciales y artifactuales del personaje en sí los que revelan algo de su entidad como persona, por su aspecto y por su acto, que no actos, ya que por lo general sólo les da tiempo a hacer una sola acción, y quedan desdibujados como roles. Muchas de sus acciones son transitivas sin resolver, afectan a terceros pero desconocemos cómo será el resultado de dicha acción, quedando abierto, resolución que generalmente no es ni sugerida. También se observa en la microforma audiovisual mucho personaje que presenta estado y no actuación.

- Espacios. Si la falta de caracterización y entidad del personaje es un hecho en la microforma, más lo es con respecto al espacio. De la historia lo importante suele ser el personaje y su momento captado; el espacio queda en un lugar vacío de importancia, quedando como espacios no construidos, limitándose a representar el lugar donde habita el personaje. Sólo se trabaja con especial interés el espacio en nano y micrometrajes que están al límite de lo narrativo y dentro de la experimentalidad micropoética audiovisual ${ }^{20}$.

Como se observa en estas características narrativas, no existe condensación de elementos, muy al contrario la simplificación nos lleva a hablar de una esquematización de todas las categorías narrativas. Lo importante en estos relatos es presentar el momento adecuado, sin condesar nada del pasado o del futuro, ni acumular elementos para la percepción. La presentación de un instante realza el hecho en sí mismo y a sus actores; en ocasiones la nimiedad de los instantes seleccionados para ser contados haría que, ensartados en una cadena de acontecimientos superior, no se reparara en él. Al aislarlo de su hipotética cadena queda único, realzado y propuesto para la reflexión.

\footnotetext{
${ }^{20}$ Se pueden visionar textos experimentales de este calibre de todo el mundo y con esta duración, no narrativos, en el marco del QuickFlick World (http://www.qfworld.tv/welcome/ 15/05/09).
} 


\section{CONCLUSIONES. Pequeño final}

Muchos son los teóricos que están de acuerdo al afirmar que la multimedialidad ha generado un nuevo equilibrio audiovisual que ha favorecido el resurgir del estilo narrativo basado en la fragmentación y la recomposición. Pero habría que añadir que en dicho estilo el fragmento ha llegado a desligarse de su todo convirtiéndose en un nuevo todo, y aunque breve con coherencia y sentido comunicativos y narrativos. Querer concluir más allá del análisis de algo que está empezando a nacer sería una temeridad, más aún cuando el trabajo sobre la microforma audiovisual se expande como derecho democrático de la creación horizontal y anónima.

Aun no sabiendo por qué caminos terminarán corriendo estos creadores, lo que sí es cierto es que estamos ante un buen terreno para lo esquematizado, lo elíptico, la ambigüedad y el símbolo; terreno, por otro lado, resbaladizo para las escasas aptitudes y dominios de técnicas. No son trabajos más fáciles de realizar que un corto, como tampoco éste lo es con respecto a un largo. La misma intensidad de trabajo aunque durante menos tiempo desemboca en la realización de un nano o micrometraje de calidad narrativa. El secreto de la micronarración audiovisual está en la selección del momento. Delante y detrás de la historia que se muestra hay más historia y la habilidad del guionista consiste en ofrecer ese momento de tal modo que el espectador se interese y recree el antes y el después a su medida, como co-creación. Como dicen Howard y Mabley (1995), la habilidad del guionista es "the ability to force the audience to see only what the storyteller chooses". Estos mismos autores recomiendan: "Make your film start like most films end" y estos cortos lo hacen, sólo que empiezan y terminan en el mismo momento.

No hay tiempo para más. 


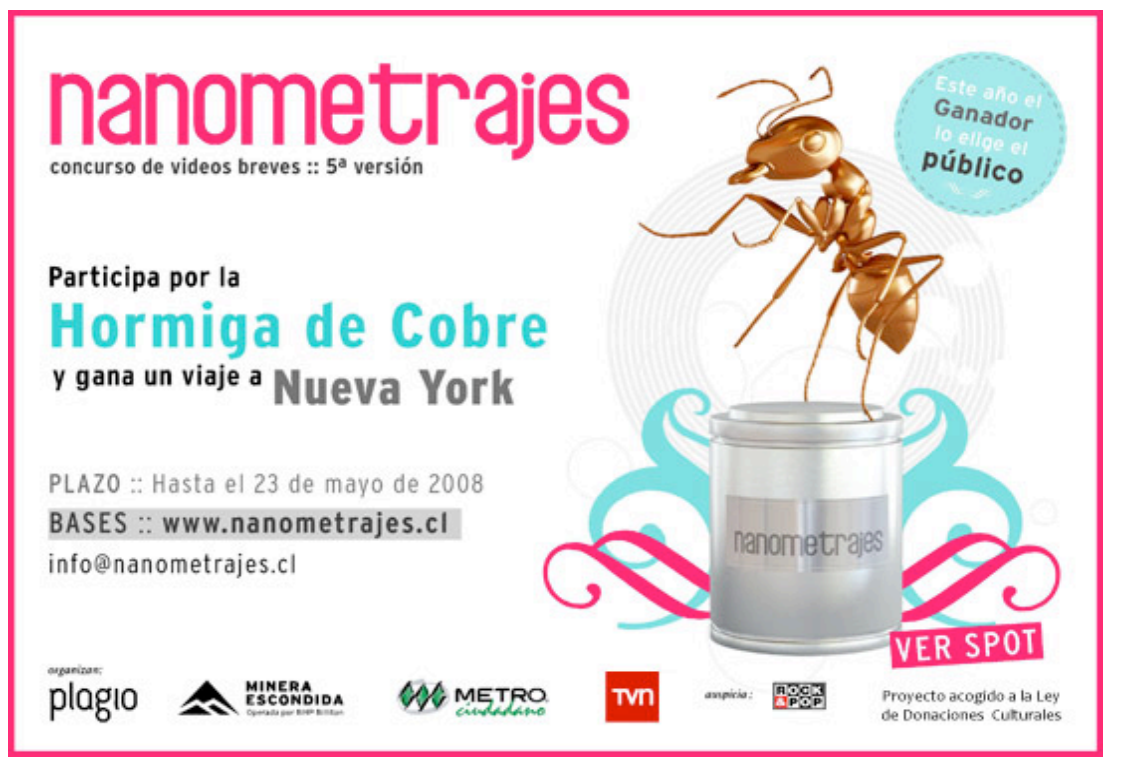

\section{REFERENCIAS BIBLIOGRÁFICAS}

AMITRANO, Alessandra (1998): El cortometraje en España: una larga historia de ficciones breves, Valencia, Generalitat Valenciana.

ANDRÉS, Irene (2001): “Tendencias del microrrelato español”, en El cuento de la década de los noventa. Actas del X Seminario Internacional del Instituto de Semiótica Literaria, Teatral y Nuevas Tecnologías de la UNED, Madrid, Visor, pp.659-674.

CALVINO, Italo (1989): Seis propuestas para el próximo milenio, Madrid, Siruela.

CERÓN, Juan Francisco (coord.) (2002): Años de corto: apuntes sobre el cortometraje español de los noventa, Murcia, Publicaciones de la Universidad de Murcia.

COOPER, Pat \& DANCYGER, Ken (1998): El guión de cortometraje, Madrid, IORTV.

GÓMEZ TRUEBA, Teresa (2008): “Acercamiento del camino estético que nos condujo al microrrelato", en Ínsula, no 741, monografía sobre el microrrelato en España, pp.1317.

GUTIÉRREZ CARBAJO, Francisco (2004): "Relato breve y cine: de Senel Paz a Gutiérrez Alea”, en Isaías Lerner, Roberto Nival y Alejandro Alonso (coords.): Actas del XIV Congreso de la Asociación Internacional de Hispanistas, vol, 4, pp.239-244. 
HOWARD, David \& MABLEY, Edward (1995): The Tools of Screenwriting, St. Martin's Press. http://www.exposure.co.uk/eejit/index.html (20/05/09).

IMBERT, Gerard (2008): El transformismo televisivo. Postelevisión e imaginarios sociales, Madrid, Cátedra.

KOCH, Dolores M. (2004): “¿Microrrelato o minicuento? ¿Minificción o hiperbreve?, en Francisca Noguerol (coord.): Escritos disconformes: nuevos modelos de lectura, Salamanca, Publicaciones de la Universidad de Salamanca, pp.45-52.

LAGMANOVICH, David (2006): "La extrema brevedad: microrrelatos de una y dos líneas", en Speculo, n³2, http://www.ucm.es/info/especulo/numero32/exbreve.html $(23 / 04 / 09)$.

LAGMANOVICH, David (2006): El microrrelato: teoría e historia, Palencia, Menoscuatro.

MARTEL, W. (2008): "Las doce reglas de un guión eficaz", 1, 2 y 3, en Guión actualidad, 23 de septiembre. http://www.guionactualidad.info/?article3331 (15/05/09). PEZZINI, Isabella (2005): Trailer, spot, clip, siti, banner. Le forme brevi della comunicazione audiovisiva, Roma, Meltemi.

PHILIPS, William (2001): Writing Short Scripts, Syracuse University Press.

RINCÓN, Omar (2006): Narrativas mediáticas. O cómo se cuenta la sociedad del entretenimiento, Barcelona, Gedisa.

RIVAS, Antonio (2008): "Entre el esbozo y el microrrelato", en Ínsula, no 741, monografía sobre el microrrelato en España, pp.19-22.

ROAS, David (2008). "El microrrelato y la teoría de los géneros", en Irene Andrés y Antonio Rivas (coords.): La era de la brevedad, el microrrelato hispánico. Actas del IV Congreso Internacional de Minificción, Universidad de Neuchâtel, pp.47-76.

RÓDENAS, Domingo (2006): "El microrrelato en la estética de la brevedad del Arte Nuevo", en Irene Andrés y Antonio Rivas (coords.): La era de la brevedad, el microrrelato hispánico. Actas del IV Congreso Internacional de Minificción, Universidad de Neuchâtel, pp.77-122.

RÓDENAS, Domingo (2008): “Contar callando y otras leyes del microrrelato", en Ínsula, $\mathrm{n}^{\mathrm{0}}$ 741, monografía sobre el microrrelato en España, pp.6-9.

SEMPERE, Antonio (2003): Corto, que te quiero corto: el cortometraje español en el siglo XXI, Cádiz, Fundación Municipal de Cultura. 
SILIÓ, Elisa (2009): “Así se hace una campaña”, en El País, Extra Publicidad, sábado 31 de enero, p.24-25.

TEJERO, Pilar (2001): “Anécdota y microrrelato: ¿dos géneros literarios?”, en El cuento de la década de los noventa. Actas del X Seminario Internacional del Instituto de Semiótica Literaria, Teatral y Nuevas Tecnologías de la UNED, Madrid, Visor, pp.731728.

VALLS, Fernando (2001): "La abundancia justa: el microrrelato en España", en El cuento de la década de los noventa. Actas del X Seminario Internacional del Instituto de Semiótica Literaria, Teatral y Nuevas Tecnologías de la UNED, Madrid, Visor, pp.641658.

WARDRIP-FRUIN, Noha \& HARRIGAN, Pat (eds.) (2004): First Person, New Media as Story, Performance and Game, MIT Press, Massachusset.

ZAVALA, Lauro (2002): "El cuento ultracorto bajo el microscopio", en Revista de Literatura, $\mathrm{n}^{\mathrm{o}} 128, \mathrm{pp} .539-553$.

ZAVALA, Lauro (2004): "Cine clásico, moderno y posmoderno”, en Razón y Palabra, no46. $\quad$ http://www.cem.itesm.mx/dacs/publicaciones/logos/anteriores/n46/lzavala.html $(23 / 04 / 09)$.

ZAVALA, Lauro (2004): "Las fronteras de la minificción”, en Francisca Noguerol (coord.): Escritos disconformes: nuevos modelos de lectura, Salamanca, Publicaciones de la Universidad de Salamanca.

ZAVALA, Lauro (2008): "La minificción audiovisual: hacia un nuevo paradigma en los estudios de la minificción", en Inés Andrés-Suárez y Antonio Rivas (coords.): La era de la brevedad. El microrrelato hispánico. Actas del IV Congreso Internacional de Minificción, Universidad de Neuchâtel, pp.207-230.

ZUNZUNEGUI, Santos (1996): La mirada cercana. Microanálisis filmico, Barcelona, Paidós. 